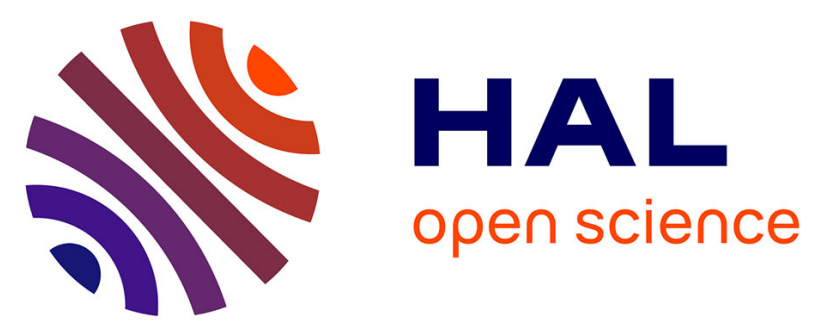

\title{
Properties of polar stratospheric clouds obtained by combined ACE-FTS and ACE-Imager extinction measurements
}

\author{
A. Y. Zasetsky, K. Gilbert, I. Galkina, S. Mcleod, J. J. Sloan
}

\section{- To cite this version:}

A. Y. Zasetsky, K. Gilbert, I. Galkina, S. Mcleod, J. J. Sloan. Properties of polar stratospheric clouds obtained by combined ACE-FTS and ACE-Imager extinction measurements. Atmospheric Chemistry and Physics Discussions, 2007, 7 (5), pp.13271-13290. hal-00303094

\section{HAL Id: hal-00303094 \\ https://hal.science/hal-00303094}

Submitted on 12 Sep 2007

HAL is a multi-disciplinary open access archive for the deposit and dissemination of scientific research documents, whether they are published or not. The documents may come from teaching and research institutions in France or abroad, or from public or private research centers.
L'archive ouverte pluridisciplinaire HAL, est destinée au dépôt et à la diffusion de documents scientifiques de niveau recherche, publiés ou non, émanant des établissements d'enseignement et de recherche français ou étrangers, des laboratoires publics ou privés. 
Properties of polar stratospheric clouds

A. Y. Zasetsky et al.

\section{Properties of polar stratospheric clouds obtained by combined ACE-FTS and ACE-Imager extinction measurements}

A. Y. Zasetsky ${ }^{1}$, K. Gilbert ${ }^{2}$, I. Galkina ${ }^{1}$, S. McLeod ${ }^{1}$, and J. J. Sloan ${ }^{1}$

${ }^{1}$ Department of Chemistry, University of Waterloo, Waterloo, Ontario N2L 3G1 Canada ${ }^{2}$ Department of Physics and Astronomy, University of Western Ontario, Ontario, Canada

Received: 13 August 2007 - Accepted: 3 September 2007 - Published: 12 September 2007

Correspondence to: J. J. Sloan (sloanj@uwaterloo.ca)

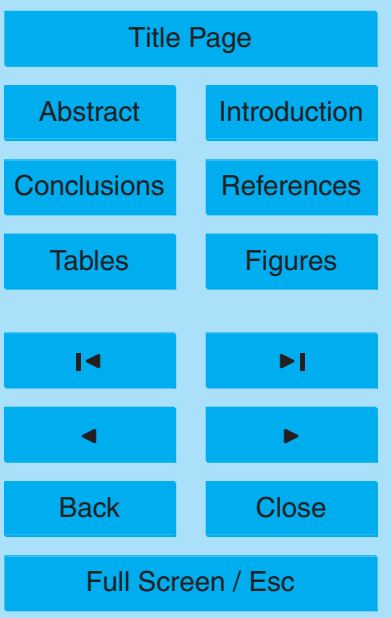

Printer-friendly Version

Interactive Discussion 


\section{Abstract}

We report the compositions and size distributions of aerosol particles in typical polar stratospheric clouds (PSCs) observed between 24 January and 28 February 2005 in the Arctic stratosphere. The results are obtained by combining the extinction mea5 surements made by the Atmospheric Chemistry Experiment (ACE) Fourier-Transform Spectrometer and the visible/near IR imagers on the SCISAT satellite. The extended wavenumber range provided by this combination $\left(750\right.$ to $\left.20000 \mathrm{~cm}^{-1}\right)$ enables the retrieval of aerosol particle sizes between 0.05 and $10 \mu \mathrm{m}$ as well as providing extensive information about the compositions. Our results indicate that liquid ternary solutions with a high $\left(>30 \mathrm{wt} \%\right.$ ) content of $\mathrm{HNO}_{3}$ were the most probable component of the clouds at the $\left(60-70^{\circ} \mathrm{N}\right)$ latitudes accessible by ACE. The mean size of these ternary aerosol particles is in the range of 0.3 to $0.8 \mu \mathrm{m}$. Less abundant, although still frequent, were clouds composed of NAT particles having radii in the range of $1 \mu \mathrm{m}$ and clouds of ice particles having mean radii in the $4-5 \mu \mathrm{m}$ range. In some cases, these last two 15 types were found in the same observation.

\section{Introduction}

To a large extent, the depletion of polar stratospheric ozone is controlled by the presence of PSCs, which at very low temperatures, can be quite extensive (von Hobe et al., 2006). Many satellite-based PSC observations, including those by POAM (Polar Ozone and Aerosol Measurement), SAGE (Stratospheric Aerosol and Gas Experiment), CLAES (Cryogenic Limb Array Etalon Spectrometer), ISAMS (Improved Stratospheric and Mesospheric Sounder), MIPAS (Michelson Interferometer for Passive Atmospheric Sounding) and ILAS (Improved Limb Atmospheric Spectrometer, Fromm et al., 2003; Hopfner et al., 2002; Lambert et al., 1996; Massie et al., 1997; Sasano et al., 2005) have provided a multi-decade record that shows that there is a good correlation between ozone depletion and PSC volume, both of which increase dramatically with
Properties of polar stratospheric clouds

A. Y. Zasetsky et al.

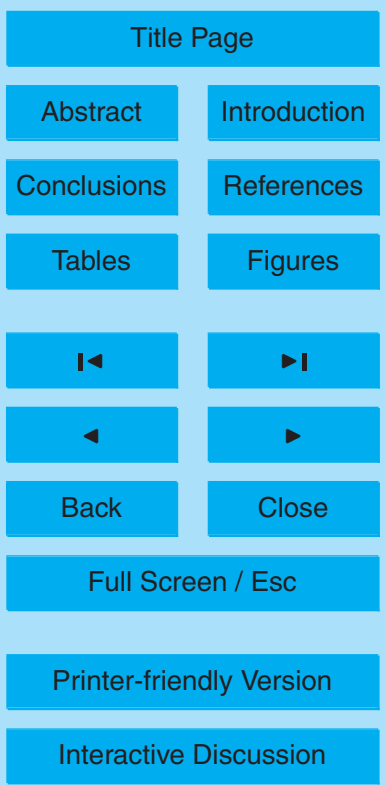

EGU 
decreasing stratospheric temperatures (Rex et al., 2006).

Both the bulk and surfaces of stratospheric aerosol particles provide sites where inert chlorine is converted into active forms that can then be photolysed to form $\mathrm{Cl}$ and $\mathrm{ClO}$ radicals, initiating ozone depletion (Solomon, 1999; Tilmes et al., 2006; MacKenzie

5 et al., 2000). At reduced temperatures, the condensation of $\mathrm{HNO}_{3}$ onto pre-existing aerosol particles causes denitrification of the stratosphere (Tabazadeh et al., 2000), which delays the conversion of reactive $\mathrm{ClO}$ to the more inert $\mathrm{ClONO}_{2}$. The clouds resulting from this process are composed mostly of $\mathrm{HNO}_{3}$ (in terms of weight fraction) and form an important subset of PSCs. At even lower temperatures, clouds composed 10 primarily of ice particles can form (Blum et al., 2006) which, in some cases, are thought to serve as nuclei for further deposition of nitric acid as NAT (Fueglistaler et al., 2003). Laboratory measurements, in combination with some of these observations, have also led to the suggestion that under some conditions, PSCs also may consist of droplets of a supercooled ternary solution (STS) of $\mathrm{H}_{2} \mathrm{SO}_{4}, \mathrm{HNO}_{3}$ and $\mathrm{H}_{2} \mathrm{O}$ (Larsen et al., 2000; 15 Massie et al., 1998; Norman et al., 2002). All these components can be thought of as members of the STS system, the equilibrium properties of which under stratospheric conditions are now well-documented (Carslaw et al., 1995). The formation of these PSCs is expected to become more frequent and extensive as stratospheric cooling by greenhouse gases increases (Knudsen et al., 2004; Schnadt et al., 2002; Danilin et al., 20 1998).

Much of the work in this area is designed to provide information that will enable stratospheric models to predict accurately the conditions under which PSCs form (Davies et al., 2005). Although many studies have been conducted, this goal has not yet been achieved. To date, only a very small fraction of the PSCs that form during 25 any particular winter have been observed and in general, each measurement only retrieves a subset of the relevant PSC properties (size distribution, composition, phase, etc.). In most cases the measurements are somewhat indirect, relying on assumptions about some properties (e.g. composition) that are not observed directly. Moreover, the physical and chemical conditions of the stratosphere vary considerably from one year

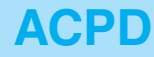

7, 13271-13290, 2007

Properties of polar stratospheric clouds

A. Y. Zasetsky et al.

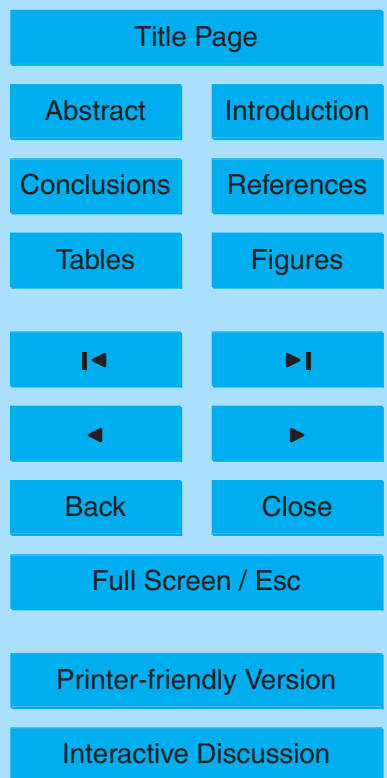

EGU 
to the next, further reducing the number of cases where comparable measurements can be made under similar conditions of temperature and gas phase composition. As a result, our knowledge of the kinetics of nucleation, phase transitions, and growth of PSC particles, is still incomplete. These uncertainties, complicated by complex polar 5 vortex dynamics, make it difficult to model the formation and temporal evolution of polar stratospheric clouds.

In the following, we report the simultaneous measurement of the size distribution and composition of selected PSCs observed by the ACE-FTS and the NIR and visible Imagers on the SciSat satellite (Bernath et al., 2005). The results were obtained using 10 a retrieval procedure developed in our group (Zasetsky et al., 2007) that uses atmospheric extinction measurements ranging across the mid-infrared, near- infrared and visible regions. The absorption features recorded by the FTS in the mid infrared starting at about $750 \mathrm{~cm}^{-1}$ provide information on the chemical composition of aerosol particles, while the extinction measurements in the extended spectral region from $750 \mathrm{~cm}^{-1}$ 15 up to $20000 \mathrm{~cm}^{-1}$ put tight restrictions on the retrieved size distribution of the aerosol particles.

\section{Remote sensing measurements}

The instruments on the SCISAT satellite operate in solar occultation mode. The FTS has a spectral bandwidth of 750 to $4170 \mathrm{~cm}^{-1}(2.4$ to $13.3 \mu \mathrm{m})$ and a resolution of $0.02 \mathrm{~cm}^{-1}$. In the present work, we have analyzed sunrise observations made during the winter of 2005. The tangent points for the occultations showing PSC events during this period are clustered in the longitude range between $25^{\circ} \mathrm{W}$ and $70^{\circ} \mathrm{E}$ and between latitudes $60^{\circ} \mathrm{N}$ and $67^{\circ} \mathrm{N}$. Overall, 20 optically dense clouds - cases where the total aerosol condensed phase volume exceeds $0.5 \mu \mathrm{m}^{3} / \mathrm{cm}^{3}$ - were observed. The first cloud analysed was observed on 24 January 2005 at $65^{\circ} \mathrm{N}$ and $53^{\circ} \mathrm{E}$. The highest frequency of cloud observations was between 26 January and 28 February 2005.

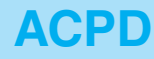

7, 13271-13290, 2007

Properties of polar stratospheric clouds

A. Y. Zasetsky et al.

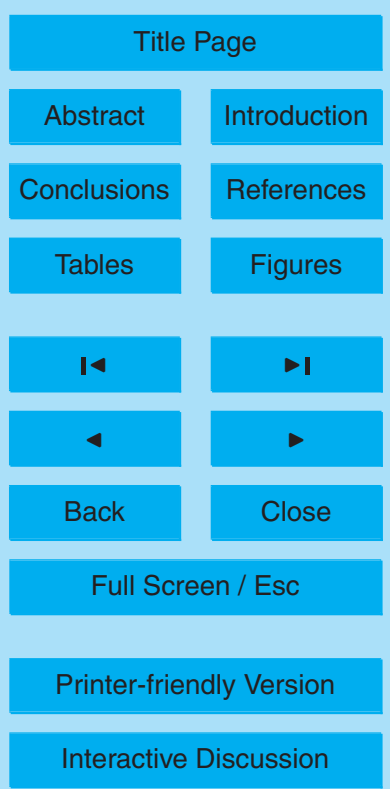

EGU 


\section{Retrieval details}

The procedure for retrieval of the aerosol size distributions and volume densities is based on the assumption that the measured aerosol spectrum is a linear superposition of the extinction spectra of all sizes and compositions of the particles in the observed 5 PSC. The technique is based on a weighted least squares minimization procedure, in which the weighting coefficients depend on the structure of the extinction spectra. The weighting procedure assigns higher weights to the spectral regions least affected by the gas phase absorption. It is also designed to take account of the contribution of spectral regions having heavily overlapped gas phase bands that mimic the broad absorption features of condensed phases. The retrieval uses a library reference spectra, which are computed monodisperse extinction spectra of the components expected to occur in the observed spectrum. It uses these reference spectra in a least squares approach that varies the size distribution to minimize the square of the difference between the (weighted) measured spectrum and trial spectra computed for a range of assumed compositions and sizes, as shown in the following expression:

$$
\min _{P}\|\mathbf{W}(\boldsymbol{M}-\mathbf{K} \cdot \boldsymbol{P})\|^{2}
$$

where $\boldsymbol{M}$ is the measured spectrum, $\mathbf{W}$ is the weight matrix, $\mathbf{K}$ is the library of reference spectra and $\boldsymbol{P}$ is the size distribution vector on which the (non-negative) least squares minimization is done. In recent laboratory tests (Zasetsky et al., 2007) we have shown that this procedure returns accurate and unique size distributions for all components if the signal to noise ratio is not too low. Both the sample complexity and the signal to noise affect the success of any given retrieval, but as an example, in recent laboratory experiments on the ice/water system, we have demonstrated the ability of the procedure to determine the relative amounts of ice crystals and water droplets in an ice/water aerosol to a level of better than $\pm 3-5 \%$ in the presence of water vapour at temperatures between $-40^{\circ} \mathrm{C}$ and $0^{\circ} \mathrm{C}$. For remote sensing applications such as the present one, the errors in the retrievals are largely determined by interference from the spectra

Properties of polar stratospheric clouds

A. Y. Zasetsky et al.

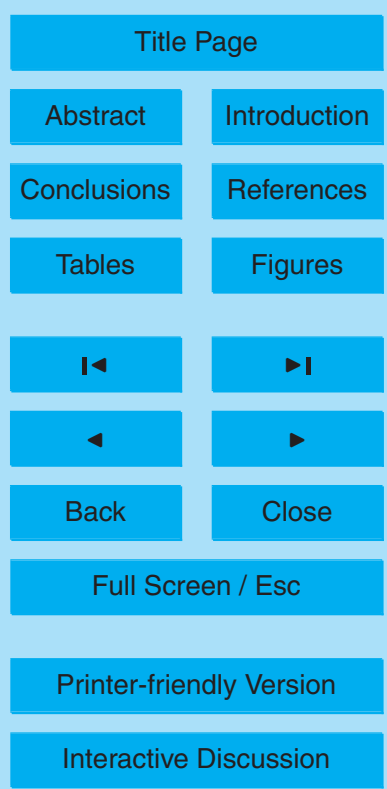


of the gas phase components. Since this interference is in the high frequency part of the signal, we use a wavelet filter that retains only the low frequency components as the first step in the analysis.

The reference spectra, $\mathbf{K}$, are a set of 96 monodisperse spectra for each chemical 5 component sought. In this case, they cover the size range from $0.05 \mu \mathrm{m}$ to $12 \mu \mathrm{m}$. The lower limit in this range is determined by the shortest wavelengths in the observed spectrum because for particle sizes much smaller than the shortest wavelength, there is too little scattering to give size information. In the case of this work, the inclusion of the visible/NIR wavelengths detected by the imagers extended the measurable particle 10 size range down to $0.05 \mu \mathrm{m}$. The upper limit is the size at which the change in the particle spectrum with increasing size becomes smaller than the noise. Since the noise in these remote sensing measurements is largely due to gas phase interference, this upper limit is altitude dependent, but we have taken $12 \mu \mathrm{m}$ as a reasonable average value for these measurements.

15 The reference spectra of liquid droplets are computed using the Mie approximation (Bohren et al., 1983); for solid hydrates and ice particles, the discrete dipole technique (Draine et al., 1994) was used. The indices of refraction for the STS droplets were obtained from Biermann et al. (2000) and those for the crystalline hydrates were calculated using the refractive indices of Niedziela et al. (1998) for NAD, Carslaw et al. (1995) for NAT and Clapp et al. (1995) for ice. In order to include the extinction data in the near infrared and visible region, the refractive indices were extended to higher frequencies by the subtractive Kramers-Kronig integration technique with the anchor point value (refraction at infinite frequency $n_{\infty}$ ) taken from Luo et al. (1996) for the STS system and from Warren (1984) for ice. The value of $n_{\infty}$ for NAT was taken to be 1.44 at $15822.7 \mathrm{~cm}^{-1}$ (Toon et al., 1994).

The imagers consist of two channels at 0.527 and $1.020 \mu \mathrm{m}$. The detectors in these channels are filtered $256 \times 256$ pixel CMOS arrays that are binned by a factor of 2 or 4 during use. The total imager field of view is $30 \mathrm{mrad}$, or a little more than three times the angular diameter of the Sun. By comparison, the FTS field of view is about 1.25 mrad.

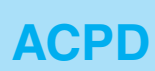

7, 13271-13290, 2007

\section{Properties of polar stratospheric clouds}

A. Y. Zasetsky et al.

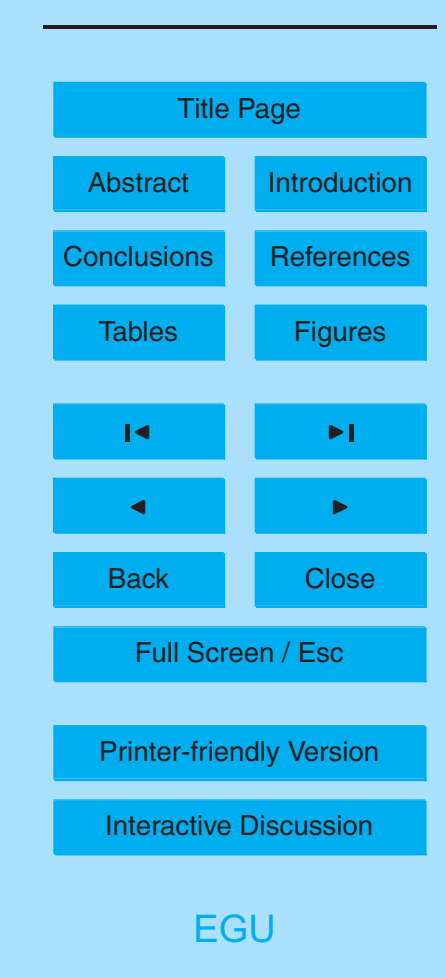


During an occultation, the two imager channels provide line-of-sight total transmission measurements coaxial with the FTS observation by taking ratios of the intensities of the sun images with an exo-atmospheric sun image (Gilbert et al., 2006). These line-ofsight transmission profiles are inverted to produce altitude profiles of total atmospheric

5 extinction, which is one of the standard data products from the SciSat mission (Boone et al., 2005). For the present work, the two imager measurements were combined with the infrared spectra to extend the high frequency end of the spectral range from $4170 \mathrm{~cm}^{-1}$ to $18975 \mathrm{~cm}^{-1}$, thereby extending the range of particle sizes that could be retrieved down to $0.05 \mu \mathrm{m}$, as mentioned above.

10 Correction for the absorption by $\mathrm{O}_{3}$ and $\mathrm{NO}_{2}$ at $0.527 \mu \mathrm{m}$ was done using the vertical VMR profiles from the ACE level 2 data (Boone et al., 2005) and the temperature dependent cross-section values from Burkholder et al. (1994); Harder et al. (1997). The Rayleigh scattering contribution by air was also subtracted from the total extinction using the method described in Bucholtz (1995) The continua of water vapor, nitrogen, 15 oxygen, carbon dioxide, and ozone were computed using the MT_CKD model (Mlawer et al., 2004) and subtracted from the total extinction. The temperatures and tangent heights used are those provided by the ACE level 2 retrieval (Boone et al., 2005).

The total error is computed as a combination of the statistical error of the least squares fitting and the uncertainty associated with the particle shape and the finite length of the spectral region. We refer readers to our recent work for more details (Zasetsky et al., 2007).

\section{Results}

Figure 1 illustrates the atmospheric extinction at two altitudes for observations having a PSC in the field of view (left side) and those of cloud-free scenes (right side). The spectra after the intense gas phase lines are reduced using a wavelet filter (Zasetsky et al., 2004). These dotted spectra are the input to the retrieval procedure. The latter

Properties of polar stratospheric clouds

A. Y. Zasetsky et al.

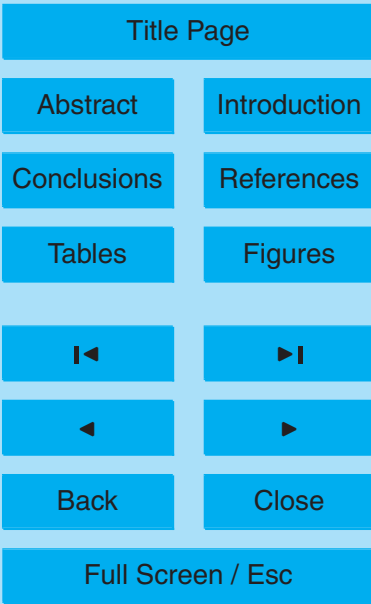

Printer-friendly Version

Interactive Discussion 
applies a weight function to de-emphasize dense bands such as those near 1000 , 2400,3600 and $3700 \mathrm{~cm}^{-1}$, which are so heavily overlapped that they appear to be continua. The procedure then calculates a least squares fit to the dotted spectrum using the reference spectra of the chemical components that have been selected for 5 the retrieval. The superposition of reference spectra giving the best fit is shown by the black solid line in each panel. Clearly, this reproduces most of the variation in the baseline, and thus can be taken to represent the signature of the PSC.

The fact that the best fit spectrum does not reproduce the dotted one exactly illustrates an important point about the approach. The dotted spectrum is only an approximation to the true condensed phase spectrum - it contains residual gas phase interference, for example - but this need not have an adverse effect on the retrieval. Because the centre frequencies of the absorption bands in the reference spectra of a specific chemical component do not vary much with particle size, the locations of these features give reliable information about the chemical composition. Similarly, the

size information is contained in the widths (and sometimes the shapes) of the extinction bands. As a result, if the reference spectra of a given component reproduce one or more of the major features in the measured spectrum, then the presence of that component in the observed sample can be considered to be proven. Moreover, if all significant features in the measured spectra are reproduced, then it can be concluded that the composition of the sample has been determined. The relative intensities of the characteristic features, of course, give the amount of that component present in the sample. On this basis, we have retrieved the compositions of six representative clouds at the altitudes of their maximum intensities and listed these in Table 1.

\section{Discussion}

25 The ACE observations of Arctic PSCs for this time period can be divided into two types. One type features an enhanced aerosol extinction intensity greater than $0.25 \times 10^{-2} \mathrm{~km}^{-1}$ throughout the entire ACE-FTS wavenumber range. The high ex-
Properties of polar stratospheric clouds

A. Y. Zasetsky et al.

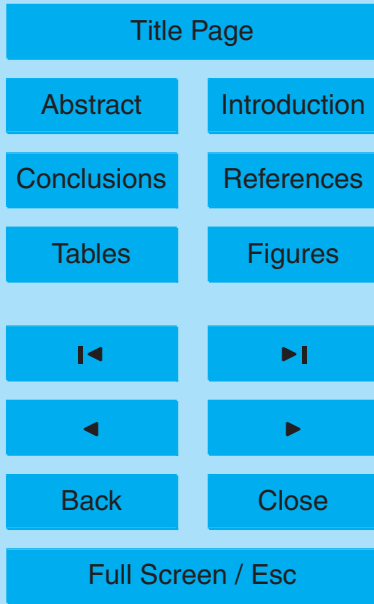

Printer-friendly Version

Interactive Discussion 
tinction and relatively featureless spectrum suggests the presence of large $(>1 \mu \mathrm{m})$ aerosol particles (there is little structure in the spectra of large particles). The other and more common type of observation has a smaller average atmospheric extinction on the order of $10^{-3} \mathrm{~km}^{-1}$ or less and more structure in the spectrum, suggesting the 5 presence of smaller particles.

The most optically dense clouds were located at $65^{\circ} \mathrm{N}, 25^{\circ} \mathrm{E}$ (observed on 28 January 2005) and at $65^{\circ} \mathrm{N}, 25^{\circ} \mathrm{E}$ (26 January 2005). Our retrieval shows that the aerosol contribution to the total extinction in these clouds is dominated by ice particles, which constitute about $70 \%$ of the total aerosol volume. The retrieved condensed phase 10 spectrum of the first of these clouds is shown as the grey plot in Fig. 2. The vertical extent of the cloud is from $18 \mathrm{~km}$ to $23 \mathrm{~km}$. The maximum cloud density is at $21 \mathrm{~km}$ and the best fit and volume size distributions at this altitude are shown in Figs. 2 and 3 , respectively. The FTS measurement (after wavelet filtering and retention of the smooth component) is shown by the wide grey curve between 800 and $4000 \mathrm{~cm}^{-1}$. (The width of this curve reflects the random noise in the retrieved signal.) This shows that the condensed phase extinction intensity is above $0.25 \times 10^{-2} \mathrm{~m}^{-1}$ throughout the entire FTS wavenumber range The two points derived from the imager measurements are shown near 10000 and $20000 \mathrm{~cm}^{-1}$. The hatched rectangles are regions of heavy gas phase interference that have been assigned weights of zero in the retrieval. The best fit spectrum is given by the solid black line and the spectra of the two components (NAT and ice) that make up the total retrieved spectrum are also shown as dashed and dotted curves respectively. The band near $820 \mathrm{~cm}^{-1}$ (see inset) is characteristic of NAT (Hopfner et al., 2002). Although this band exists in both the liquid and crystalline states, it is much weaker in liquids. On the basis of the strength of the band and 25 the fact that it is centered at $820 \mathrm{~cm}^{-1}$, we conclude that NAT and not liquid nitric acid solution is present. Similarly, this band shows that the particles are not nitric acid dihydrate (NAD) because the maximum in the corresponding band for NAD is at a lower frequency (about $810 \mathrm{~cm}^{-1}$ ). NAT alone is not adequate to reproduce completely the observed spectrum, however. Ice must also be included in the retrieval to achieve the

Properties of polar stratospheric clouds

A. Y. Zasetsky et al.

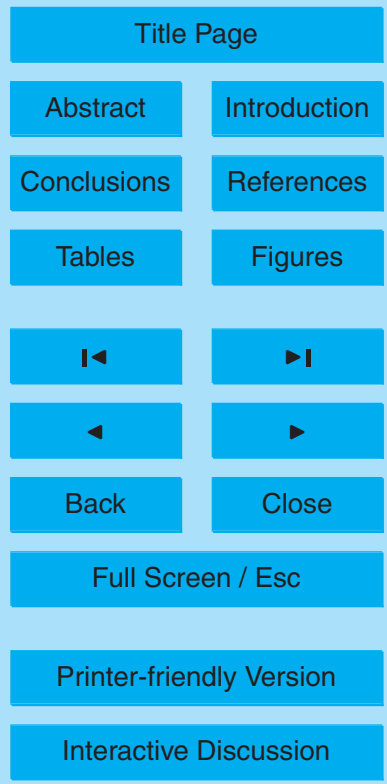

EGU 
best fit, which is shown by the black line superimposed on the measured spectrum.

Figure 3 shows the size distributions of the ice and NAT particles that were obtained from the least squares retrieval. The ice component is the larger mode - the maximum in this volume size distribution is centered at a radius of about $5 \mu \mathrm{m}$. The NAT is 5 smaller, with a size distribution that peaks near $1 \mu \mathrm{m}$. Due to the nature of the occultation measurement, it is not possible to determine whether the ice and NAT components are physically separated along the horizontal line of sight - and hence are an external mixture - or whether they are present in the same region of space. In the latter case, they could either be an external mixture of ice and NAT particles or an internal 10 mixture of ice and NAT that originates from the freezing of dilute $\mathrm{HNO}_{3}$ droplets. Laboratory studies of the phase diagram of dilute $\mathrm{HNO}_{3}$ aerosol droplets at stratospheric temperatures have shown (Dickens et al., 2002) that for $\mathrm{HNO}_{3}$ mole fractions in a narrow range near about $\mathrm{xHNO}_{3} \sim 0.10$, ice forms first in the droplet and NAT deposits on the ice nuclei as the supernatant solution becomes more concentrated. This is a very

narrow region in the phase diagram, however, and while it cannot be ruled out, this process must be considered to be very unlikely. It is thus most probable that the clouds observed are composed of an external mixture of ice and NAT particles.

The extinction spectrum recorded in occultation number sr7818 (17 February 2005; $71^{\circ} \mathrm{N} / 45^{\circ} \mathrm{E}$ ) is shown in Fig. 4. The best fit, which is obtained using reference spectra of liquid STS particles, is included as the black line. The corresponding volume size distribution, which peaks near $0.3 \mu \mathrm{m}$, is shown in Fig. 5 . The results shown in Figs. 3 and 5 represent the most common compositions retrieved from the ACE observations. In addition to these, pure ice clouds were sometimes retrieved as well. In all cases where ice clouds were observed, the particle sizes were larger by a factor of 2 to 4 than those of other compositions.

Although our retrieval procedure does not impose any constraints (except smoothness) on the shapes of the size distributions, we often find that the distributions have a near lognormal shape - they are close to a Gaussian or a sum of Gaussians when plotted on a logarithmic axis. It is not clear if this is an intrinsic property of the clouds
Properties of polar stratospheric clouds

A. Y. Zasetsky et al.

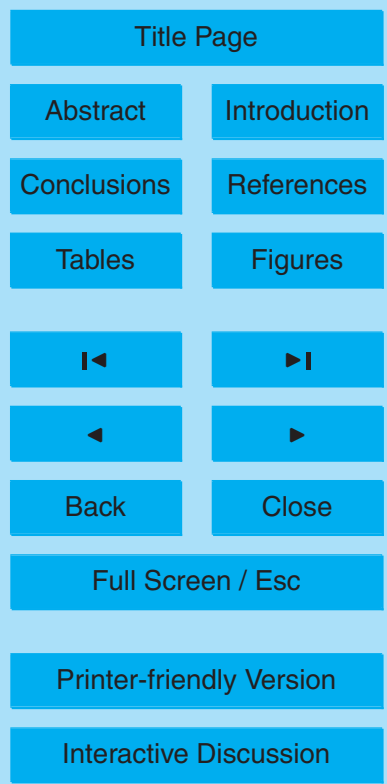

EGU 
induced, for example, by the dynamics of the vortex or the kinetics of particle growth and evaporation, but the observation is persistent over several dozens of observations.

\section{Conclusion}

We have presented the first retrievals of PSC compositions and size distributions obtained by combining the mid-IR spectral measurements of the ACE FTIR instrument with the NIR and visible Imagers on the SCISAT satellite. The addition of the NIR and visible extinction increases the accuracy in the determination of the size distributions of the smaller NAT and STS particles.

We present two cases that are typical of the results we have obtained to date. The PSCs most commonly observed consist of an STS aerosol with small droplets having radii less than about $0.5 \mu \mathrm{m}$ and usually near $0.2-0.3 \mu \mathrm{m}$. These clouds are found at higher temperatures of $195-198 \mathrm{~K}$. The other, less common clouds are composed of solid particles having the composition of NAT and/or ice. These are found at temperatures below about $195 \mathrm{~K}$. The NAT particles have radii on the order of $1 \mu \mathrm{m}$ and in the observations we have analysed to date; they are always smaller than the ice particles, which usually have average radii of $4-6 \mu \mathrm{m}$.

Acknowledgements. We are grateful for the financial support of the Canadian Space Agency and the Natural Sciences and Engineering Research Council of Canada.

\section{References}

20 Bernath, P. F., McElroy, C. T., Abrams, M. C., et al.: Atmospheric Chemistry Experiment (ACE): Mission overview, Geophys. Res. Lett., 32, 15, doi:10.1029/2005GL022386, 2005.

Biermann, U. M., Luo, B. P., and Peter, T.: Absorption spectra and optical constants of binary and ternary solutions of $\mathrm{H}_{2} \mathrm{SO} 4, \mathrm{HNO} 3$, and $\mathrm{H} 2 \mathrm{O}$ in the mid infrared at atmospheric temperatures, J. Phys. Chem. A, 104, 783-793, 2000.

Properties of polar stratospheric clouds

A. Y. Zasetsky et al.

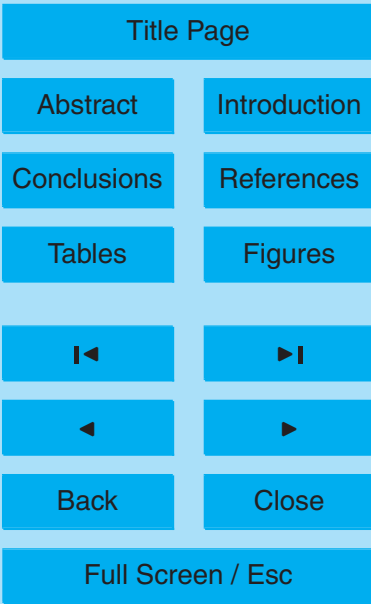

Printer-friendly Version

Interactive Discussion 
Blum, U., Khosrawi, F., Baumgarten, G., et al.: Simultaneous lidar observations of a polar stratospheric cloud on the east and west sides of the Scandinavian mountains and microphysical box model simulations, Ann. Geophys., 24, 3267-3277, 2006,

http://www.ann-geophys.net/24/3267/2006/.

5 Bohren, G. and Huffman, D.: Absorption and Scattering of Light by Small Particles, Wiley, New York, 1983.

Boone, C. D., Nassar, R., Walker, K. A., et al.: Retrievals for the atmospheric chemistry experiment Fourier-transform spectrometer, Appl. Optics, 44, 7218-7231, 2005.

Bucholtz, A.: Rayleigh-Scattering Calculations for the Terrestrial Atmosphere, Appl. Optics, 34, 2765-2773, 1995.

Burkholder, J. B. and Talukdar, R. K.: Temperature-Dependence of the Ozone AbsorptionSpectrum Over the Wavelength Range 410 to 760 Nm, Geophys. Res. Lett., 21, 581-584, 1994.

Carslaw, K. S., Clegg, S. L., and Brimblecombe, P.: A Thermodynamic Model of the System $15 \mathrm{Hcl}-\mathrm{Hno3}-\mathrm{H} 2 \mathrm{So} 4-\mathrm{H} 2 \mathrm{O}$, Including Solubilities of Hbr, from Less-Than-200 to $328 \mathrm{~K}$, J. Phys. Chem., 99, 11557-11574, 1995.

Clapp, M. L., Miller, R. E., and Worsnop, D. R.: Frequency-Dependent Optical-Constants of Water Ice Obtained Directly from Aerosol Extinction Spectra, J. Phys. Chem., 99, 63176326, 1995.

Danilin, M. Y., Sze, N. D., Ko, M. K. W., et al.: Stratospheric cooling and Arctic ozone recovery, Geophys. Res. Lett., 25, 2141-2144, 1998.

Davies, S., Mann, G. W., Carslaw, K. S., et al.: 3-D microphysical model studies of Arctic denitrification: comparison with observations, Atmos. Chem. Phys., 5, 3093-3109, 2005, http://www.atmos-chem-phys.net/5/3093/2005/.

Dickens, A. B. and Sloan, J. J.: The nucleation and freezing of dilute nitric acid aerosols, J. Phys. Chem. A, 106, 10543-10 549, 2002.

Draine, B. T. and Flatau, P. J.: Discrete-Dipole Approximation for Scattering Calculations, J. Opt. Soc. Am. A-Optics Image Science and Vision, 11, 1491-1499, 1994.

Fromm, M., Alfred, J., and Pitts, M.: A unified, long-term, high-latitude stratospheric aerosol and cloud database using SAM II, SAGE II, and POAM II/III data: Algorithm description, database definition, and climatology, J. Geophys. Res., Atmos., 108(D12), 4366, doi:10.1029/2002JD002772, 2003.

Fueglistaler, S., Buss, S., Luo, B. P., et al.: Detailed modeling of mountain wave PSCs, Atmos.

Properties of polar stratospheric clouds

A. Y. Zasetsky et al.

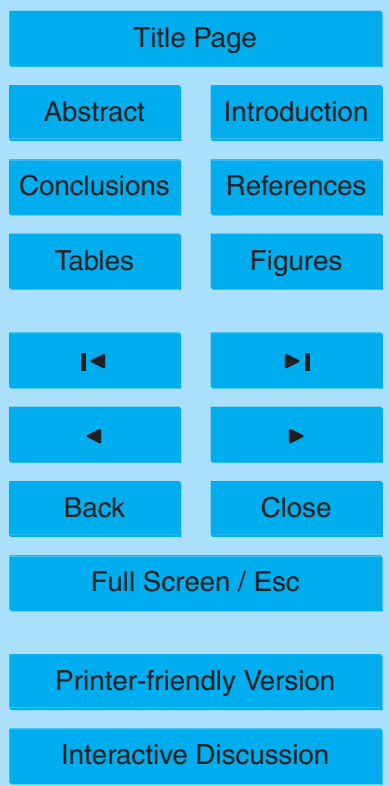

EGU 
Chem. Phys., 3, 697-712, 2003,

http://www.atmos-chem-phys.net/3/697/2003/.

Gilbert, K., Turnbull, D. N., Walker, K. A., et al.: The On-Board Imagers for the Canadian ACE SCISAT-1 Mission, J. Geophys. Res.-Atmos., 112, D12207, doi:10.1029/2006JD007714, 52006

Harder, J. W., Brault, J. W., Johnston, P. V., et al.: Temperature dependent NO2 cross sections at high spectral resolution, J. Geophys. Res.-Atmos., 102, 3861-3879, 1997.

Hopfner, M., Oelhaf, H., Wetzel, G., et al.: Evidence of scattering of tropospheric radiation by PSCs in mid-IR limb emission spectra: MIPAS-B observations and KOPRA simulations, Geophys. Res. Lett., 29(8), 1278, doi:10.1029/2001GL014443, 2002.

Knudsen, B. M., Harris, N. R. P., Andersen, S. B., et al.: Extrapolating future Arctic ozone losses, Atmos. Chem. Phys., 4, 1849-1856, 2004, http://www.atmos-chem-phys.net/4/1849/2004/.

Lambert, A., Grainger, R. G., Remedios, J. J., et al.: Validation of aerosol measurements from 15 the improved stratospheric and mesospheric sounder, J. Geophys. Res. Atmos., 101, 98119830, 1996.

Larsen, N., Mikkelsen, I. S., Knudsen, B. M., et al.: Comparison of chemical and optical in situ measurements of polar stratospheric cloud particles, J. Geophys. Res. Atmos., 105, 1491-1502, 2000.

20 Luo, B. P., Krieger, U. K., and Peter, T.: Densities and refractive indices of $\mathrm{H} 2 \mathrm{SO} / \mathrm{HNO} / \mathrm{H} 2 \mathrm{O}$ solutions to stratospheric temperatures, Geophys. Res. Lett., 23, 3707-3710, 1996.

MacKenzie, I. A. and Harwood, R. S.: Arctic ozone destruction and chemical-radiative interaction, J. Geophys. Res., Atmos., 105, 9033-9051, 2000.

Massie, S. T., Baumgardner, D., and Dye, J. E.: Estimation of polar stratospheric cloud volume and area densities from UARS, stratospheric aerosol measurement II, and polar ozone and aerosol measurement II extinction data, J. Geophys. Res., Atmos., 103, 5773-5783, 1998.

Massie, S. T., Dye, J. E., Baumgardner, D., et al.: Simultaneous observations of Polar Stratospheric Clouds and HNO3 over Scandinavia in January, 1992, Geophys. Res. Lett., 24, 595-598, 1997.

30 Mlawer, E. J., Tobin, D. C., and Clough, S. A.: A Revised Perspective on the Water Vapor Continuum: The MT_CKD Model, http://rtweb.aer.com/continuum_frame.html, 2004.

Niedziela, R. F., Miller, R. E., and Worsnop, D. R.: Temperature- and frequency-dependent optical constants for nitric acid dihydrate from aerosol spectroscopy, J. Phys. Chem. A, 102,

Properties of polar stratospheric clouds

A. Y. Zasetsky et al.

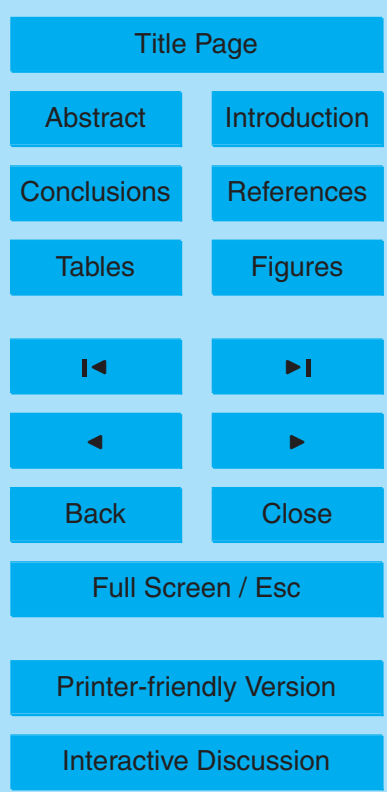


6477-6484, 1998.

Norman, M. L., Miller, R. E., and Worsnop, D. R.: Ternary H2SO4/HNO3/H2O optical constants: New measurements from aerosol spectroscopy under stratospheric conditions, J. Phys. Chem. A, 106, 6075-6083, 2002.

5 Rex, M., Salawitch, R. J., Deckelmann, H., et al.: Arctic winter 2005: Implications for stratospheric ozone loss and climate change, Geophys. Res. Lett., 33, L23808, doi:10.1029/2006GL026731, 2006.

Sasano, Y., Oshchepkov, S., Yokota, T., et al.: Characterization of stratospheric liquid ternary solution aerosol from broadband infrared extinction measurements, J. Geophys. Res., Atmos., 110, D18212, doi:10.1029/2004JD005709, 2005.

Schnadt, C., Dameris, M., Ponater, M., et al.: Interaction of atmospheric chemistry and climate and its impact on stratospheric ozone, Clim. Dynam., 18, 501-517, 2002.

Solomon, S.: Stratospheric ozone depletion: A review of concepts and history, Rev. Geophys., 37, 275-316, 1999.

15 Tabazadeh, A., Santee, M. L., Danilin, M. Y., et al.: Quantifying denitrification and its effect on ozone recovery, Science, 288, 1407-1411, 2000.

Tilmes, S., Muller, R., Engel, A., et al.: Chemical ozone loss in the Arctic and Antarctic stratosphere between 1992 and 2005, Geophys. Res. Lett., 33, L20812, doi:10.1029/2006GL026925, 2006.

20 Toon, O. B., Tolbert, M. A., Koehler, B. G., et al.: Infrared Optical-Constants of H2O Ice, Amorphous Nitric-Acid Solutions, and Nitric-Acid Hydrates, J. Geophys. Res., Atmos., 99, 25631 $25654,1994$.

von Hobe, M., Ulanovsky, A., Volk, C. M., et al.: Severe ozone depletion in the cold Arctic winter 2004-05, Geophys. Res. Lett., 33, L17815, doi:10.1029/2006GL026945, 2006.

Warren, S. G.: Optical-Constants of Ice from the Ultraviolet to the Microwave, Appl. Optics, 23, 1206-1225, 1984.

Zasetsky, A. Y., Earle, M. E., Cosic, B., et al.: Retrieval of Aerosol Physical and Chemical Properties from Mid-Infrared Extinction Spectra, J. Quant. Spectr. Radiat. Trans., 107(2), 294-305, 2007.

30 Zasetsky, A. Y., Khalizov, A. F., and Sloan, J. J.: Characterization of atmospheric aerosols from infrared measurements: simulations, testing, and applications, Appl. Optics, 43, 5503-5511, 2004.

Properties of polar stratospheric clouds

A. Y. Zasetsky et al.

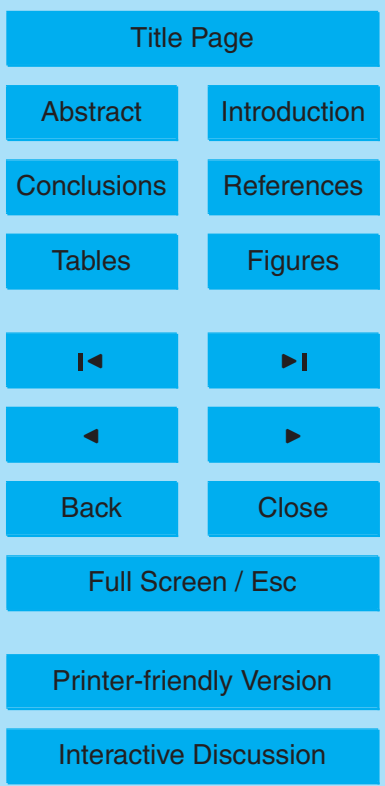




\section{ACPD}

7, 13271-13290, 2007

\section{Properties of polar stratospheric clouds}

A. Y. Zasetsky et al.

Table 1. The properties of PSCs observed by ACE between 24 and 28 January 2005.

\begin{tabular}{llllll}
\hline Occultation N & Lat/Lon & Date & NAT $\left(\mu \mathrm{m}^{3} / \mathrm{cm}^{3}\right)$ & STS $\left(\mu \mathrm{m}^{3} / \mathrm{cm}^{3}\right)$ & Ice $\left(\mu \mathrm{m}^{3} / \mathrm{cm}^{3}\right)$ \\
\hline sr7814 & $64.9 / 52.8$ & 24 Jan - & 1.6 & - \\
sr7829 & $65.0 / 46.1$ & 25 Jan - & 1.5 & 0.2 \\
sr7843 & $65.2 / 63.7$ & 26 Jan & 1.5 & - \\
sr7845 & $65.2 / 14.8$ & 26 Jan & 3.7 & - & 6.5 \\
sr7859 & $65.3 / 32.3$ & 27 Jan & - & 2.7 & 0.3 \\
sr7874 & $65.5 / 25.3$ & 28 Jan & 2.4 & & 2.8 \\
\hline
\end{tabular}

Title Page

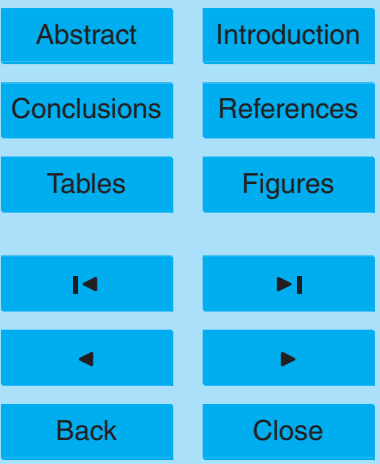

Full Screen / Esc

Printer-friendly Version

Interactive Discussion 


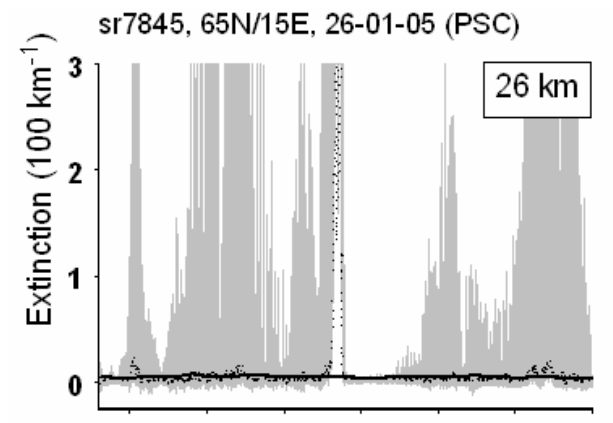

sr7786 64N/17E, 22-01-05 (PSC free)
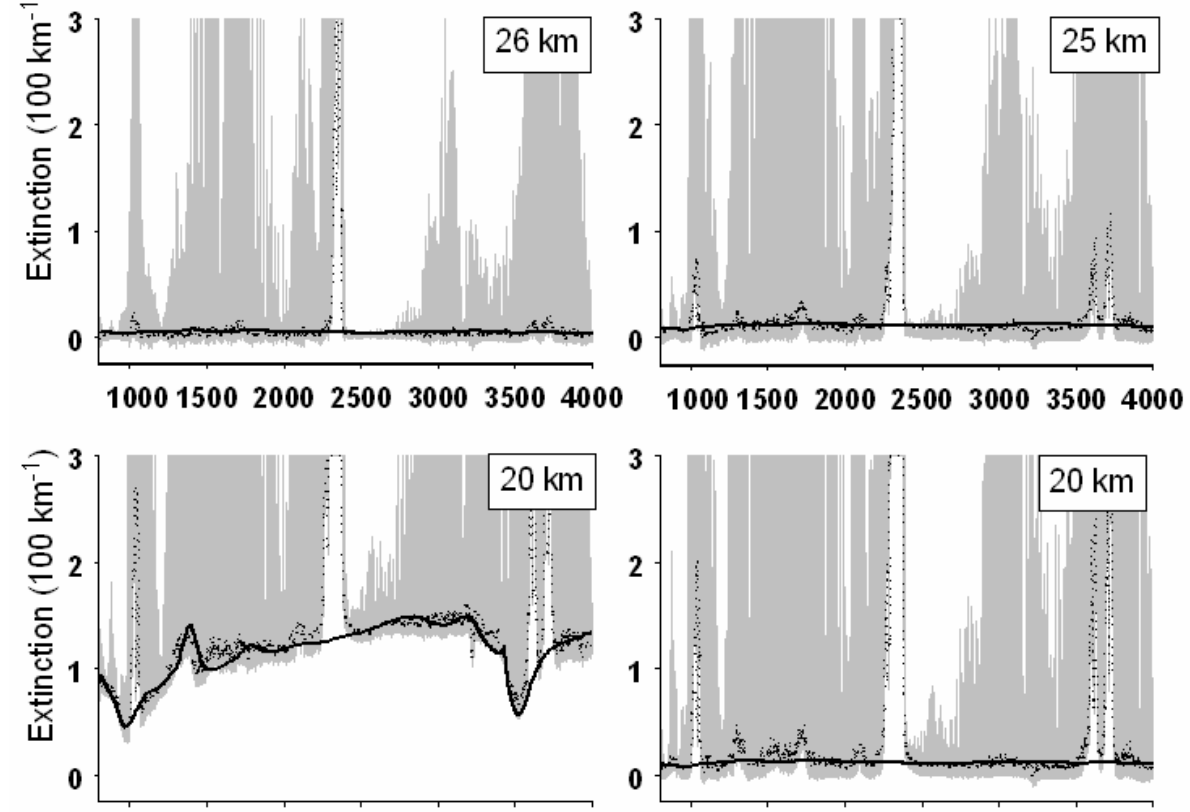

1000150020002500300035004000

Frequency $\left(\mathrm{cm}^{-1}\right)$

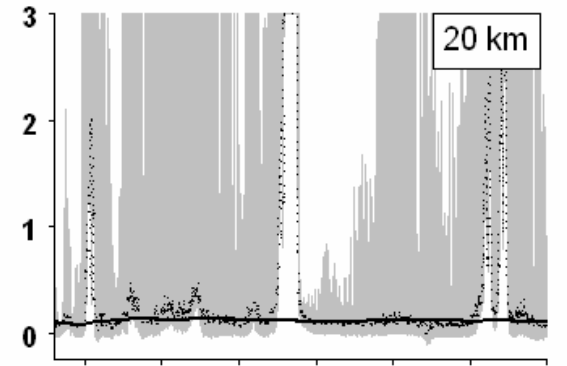

1000150020002500300035004000

Frequency $\left(\mathrm{cm}^{-1}\right)$

Fig. 1. Comparison between the spectrum of an optically dense PSC (left panels) and typical cloud free (right panels) observations. Raw ACE-FTS spectra are shown by the gray line. Solid black and dotted black lines are the best fits and smooth components of these spectra, respectively.

Properties of polar stratospheric clouds

A. Y. Zasetsky et al.

Title Page

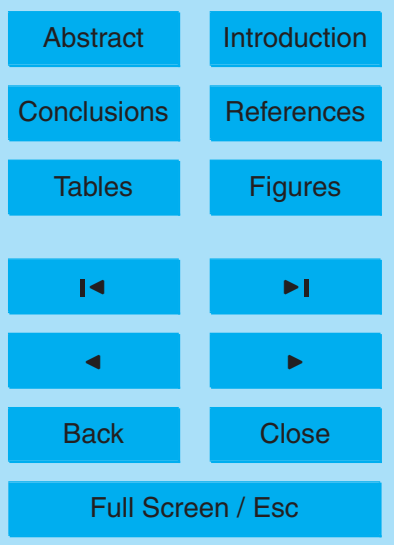

Printer-friendly Version

Interactive Discussion 


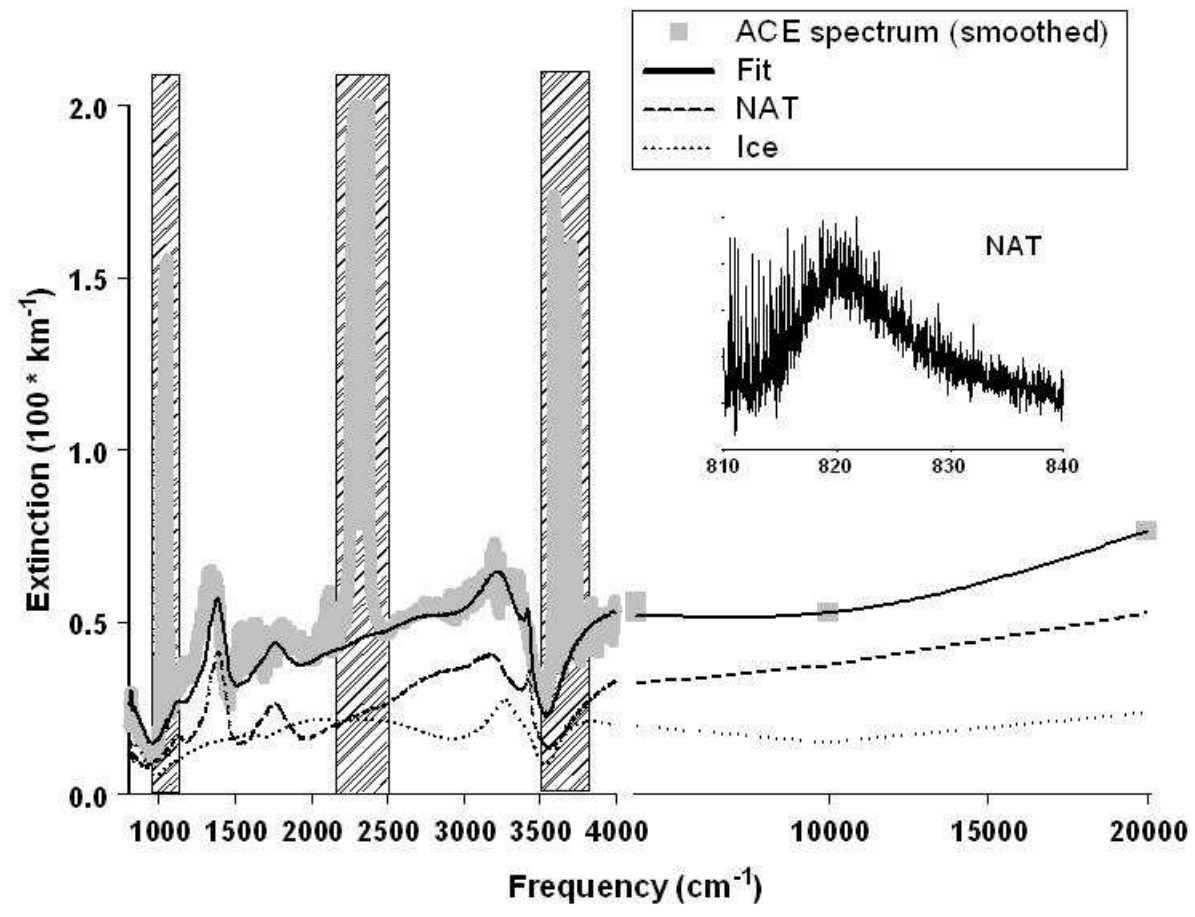

Fig. 2. Combined ACE-FTS and Imager (occultation number sr7874, 28 January 2005, $65^{\circ} \mathrm{N} / 25^{\circ} \mathrm{E}$ extinction data together with the best fit for an ice cloud. Inset shows the characteristic NAT band near $820 \mathrm{~cm}^{-1}$. The NAT and Ice contributions are shown by the dashed and dotted lines, respectively. The temperature of the observation was approximately $188 \mathrm{~K}$.

\section{ACPD}

7, 13271-13290, 2007

\section{Properties of polar stratospheric clouds}

A. Y. Zasetsky et al.

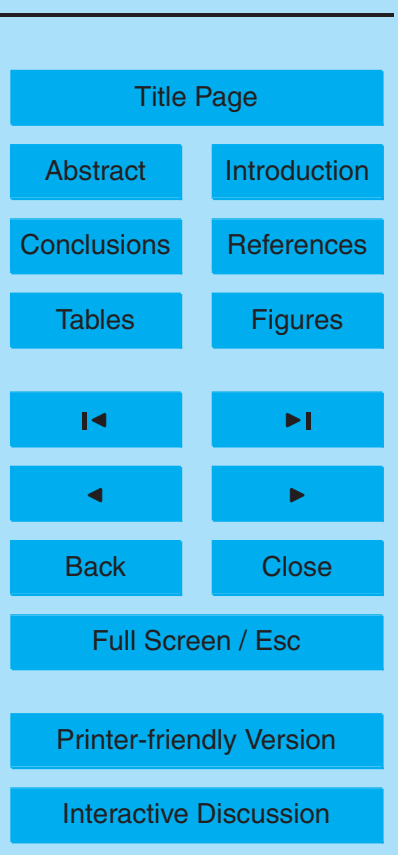

EGU 


\section{ACPD}

\section{7, 13271-13290, 2007}

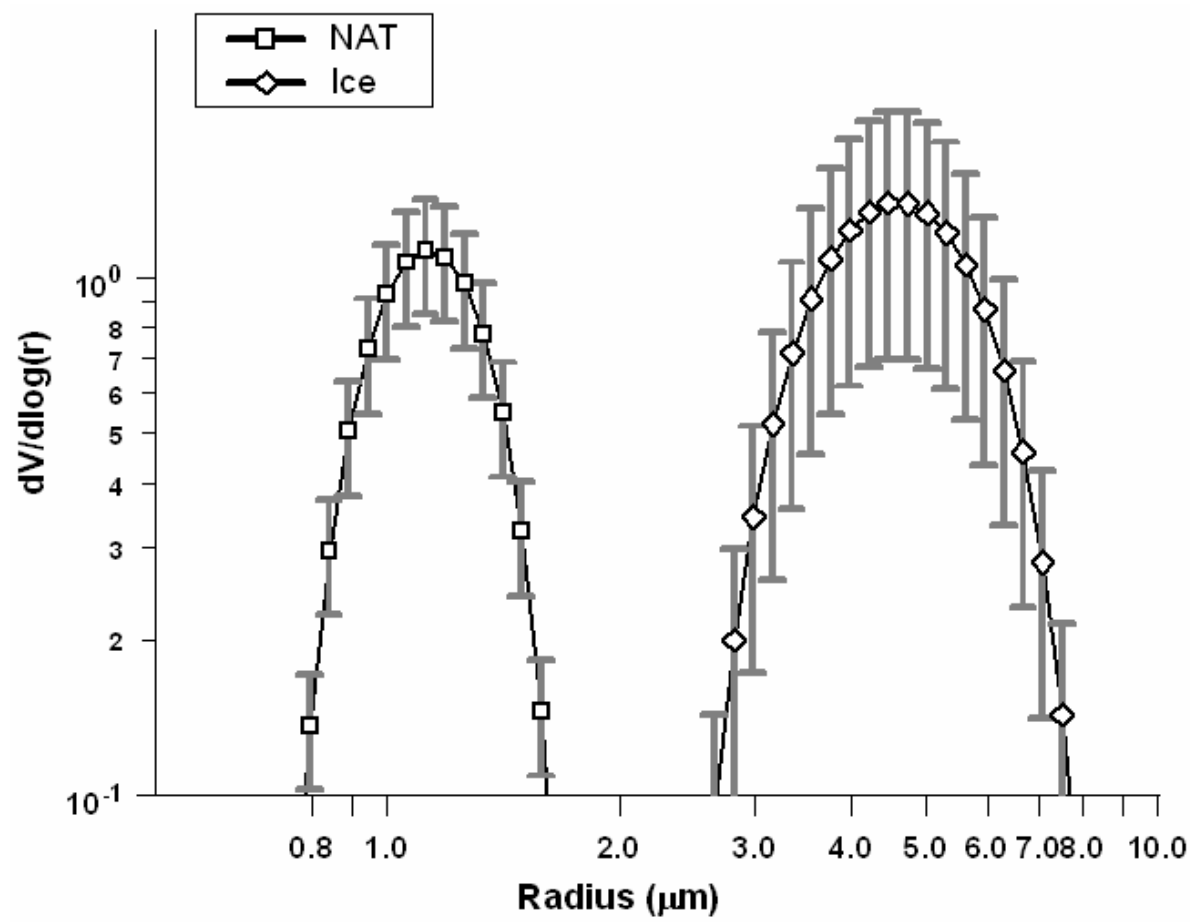

\section{Properties of polar}

stratospheric clouds

A. Y. Zasetsky et al.

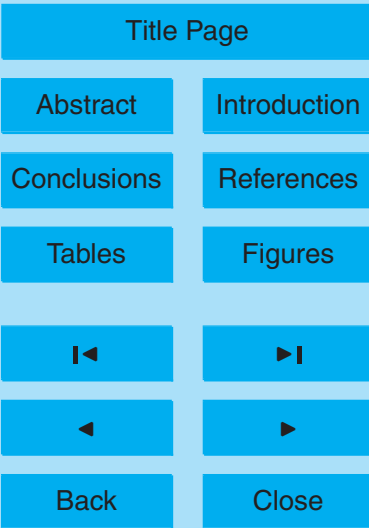

Full Screen / Esc

Printer-friendly Version

Interactive Discussion

Fig. 3. Size distribution - occultation number sr7874, 28 January $2005,65^{\circ} \mathrm{N} / 25^{\circ} \mathrm{E}$. 


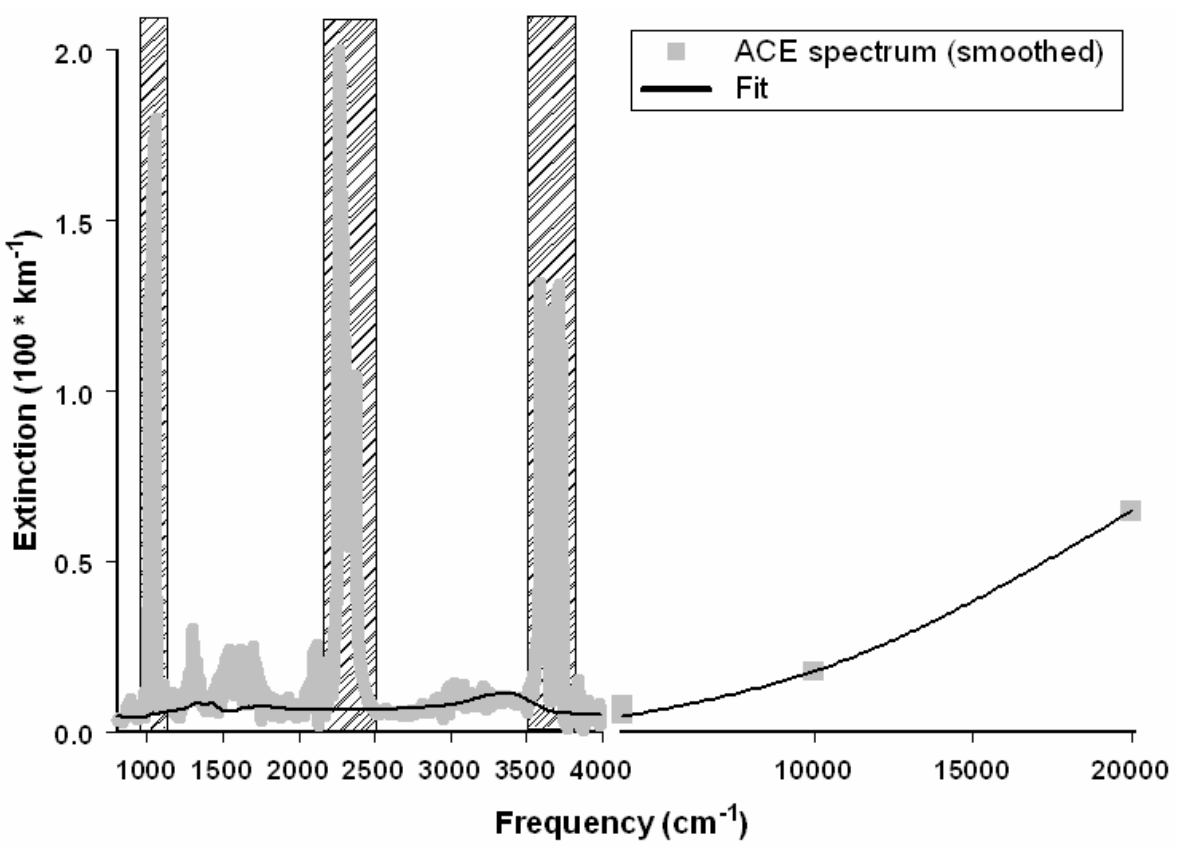

Fig. 4. Combined ACE-FTS and Imager (occultation number sr7818, 17 February 2005, $71^{\circ} \mathrm{N} / 45^{\circ} \mathrm{E}$ ) extinction data together with the best fit for a STS cloud. The temperature retrieved for this observation is $198 \mathrm{~K}$.

\section{ACPD}

7, 13271-13290, 2007

\section{Properties of polar stratospheric clouds}

A. Y. Zasetsky et al.

Title Page

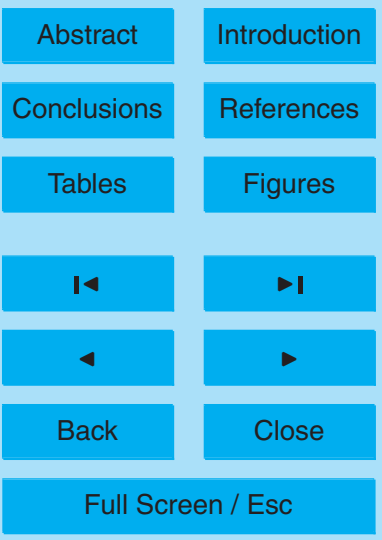

Printer-friendly Version

Interactive Discussion 


\section{ACPD}

\section{7, 13271-13290, 2007}

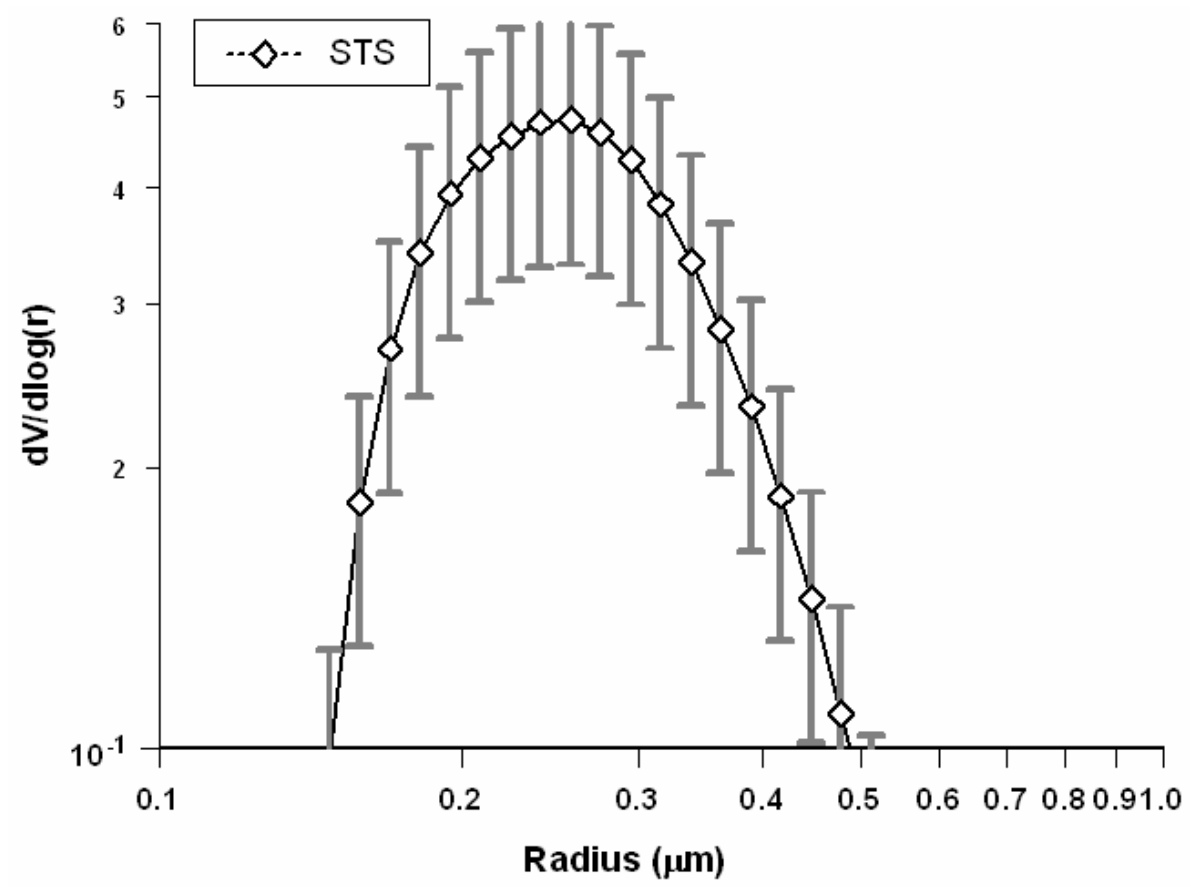

\section{Properties of polar}

stratospheric clouds

A. Y. Zasetsky et al.

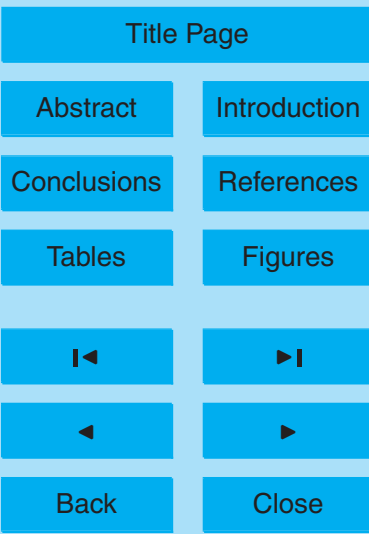

Full Screen / Esc

Fig. 5. Size distribution - occultation number sr7818, 17 February $2005,71^{\circ} \mathrm{N} / 45^{\circ} \mathrm{E}$.

Printer-friendly Version

Interactive Discussion 